\title{
Gradation of proteins and cells attached to the surface of bio-inert zwitterionic polymer brush
}

Lifu Li ${ }^{\mathrm{a}}$, Tadashi Nakaji-Hirabayashi ${ }^{\mathrm{a}, \mathrm{b}, \mathrm{c}}$, Hiromi Kitano ${ }^{\mathrm{b}, \mathrm{d} *}$, Kohji Ohno ${ }^{\mathrm{e}}$, Takahiro Kishioka ${ }^{\mathrm{f}}$, Yuki Usui ${ }^{\mathrm{f}}$

${ }^{a}$ Department of Advanced Nano- and Biosciences, Graduate School of Innovative Life Sciences, University of Toyama, Toyama 930-8555, Japan.

${ }^{b}$ Department of Applied Chemistry, Graduate School of Science and Engineering, University of Toyama, Toyama 930-8555, Japan.

${ }^{c}$ Frontier Research Core for Life Sciences, University of Toyama, Toyama 930-8555, Japan.

${ }^{d}$ Institute for Polymer-Water Interfaces, Fukujima 84, Yatsuo, Toyama 939-2376, Japan.

${ }^{e}$ Institute for Chemical Research, Kyoto University, Uji 611-0011, Japan.

${ }^{f}$ Electronics Materials Laboratory, Nissan Chemical Industries, Toyama 939-2792, Japan.

* To whom correspondence should be addressed. E-mail: kitano443116@gmail.com

The total number of words, 4638 (Main Text).

The total number of Schemes/Figures, 8 . 


\section{ABSTRACT}

A self-assembled monolayer (SAM) of a 2-bromoisobutyryl end group-carrying initiator for atom transfer radical polymerization (ATRP) was constructed on the surface of silicon wafer or glass substrates via a silane-coupling reaction. When the initiator SAM was irradiated with UV light at $254 \mathrm{~nm}$, the surface density of bromine atoms was reduced by the scission of $\mathrm{C}-\mathrm{Br}$ bonds as observed by XPS. With the surface-initiated ATRP of the zwitterionic vinyl monomer, carboxymethyl betaine (CMB), the surface density of PCMB brushes could be easily varied by changing the irradiation period of UV light prior to the polymerization. Furthermore, by using a UV-cut shutter sliding above the initiator SAM-modified substrate at a constant speed, the degree of bromine atom removal could be linearly varied along the direction of movement of the shutter. Consequently, the amount of both proteins adsorbed and cells adhered to the PCMB brush-covered substrate could easily be controlled by the gradation of the surface density of PCMB brushes, which suppressed protein adsorption and cell adhesion. Such a technique is very simple and useful for the regulation of the surface density of adsorbed proteins and adhered cells on an originally bio-inert surface.

Keywords: Atom transfer radical polymerization; Cell adhesion; Gradation; Protein adsorption; UV irradiation; Zwitterionic polymer brush. 


\section{Introduction}

For the modification of solid surfaces, so-called "polymer brushes" have been widely used. In the construction of polymer brushes, "grafting-from" and "grafting-to" procedures can be used. To obtain condensed polymer brushes, the former method has been preferentially adopted, whereas the latter can be easily pursued [1-5]. For the preparation of polymer brushes by the grafting-from method, controlled radical polymerization methods such as atom transfer radical polymerization (ATRP) [6-9], reversible addition-fragmentation chain transfer polymerization $[10,11]$, and nitroxide-mediated polymerization $[12,13]$ have been widely used.

Zwitterionic polymers have been extensively used for the construction of biocompatible surfaces [14-17]. By the vibrational spectroscopic analyses of the hydrogen-bonded network structure of vicinal water, it has been pointed out that charge-neutralized polymers including zwitterionic and amphoteric polymers are inert to vicinal water, which provides biocompatible properties to the polymer surface [18-21]. It has previously been reported that the surface of zwitterionic brushes exhibit interesting properties with respect to friction and lubricity [22-24].

Recently, the construction of surfaces with additional values, including the modification of solid surfaces with polymeric materials and micro-fabrication technology, is highly sought after [25-27].

Many research groups, including our group, have reported that surfaces modified with zwitterionic polymers can efficiently suppress protein adsorption and cell adhesion [28-32]. Furthermore, patterned surfaces of proteins and cells could be constructed using UV light or high-energy beams such as an ArF-excimer laser and focused ion beams [33-35]. Ahmad et al., for example, reported poly[oligo(ethylene glycol)methacrylate] brushes grown from photo-patterned halogen initiators using a unique technology, the selective decomposition of the C-Br bond of the initiator for ATRP by using UV light at $244 \mathrm{~nm}$ [36]. 
It is very difficult to understand cellular behaviors in vivo because various events occur simultaneously. In the literature, gradated materials have been quite useful for the construction of surfaces with a concentration gradient of cells and proteins [37-40]. The applicability of gradated materials is quite promising because a wide range of information on the interaction of biological materials can be obtained on the same surface. Until now, various methods have been reported for constructing a gradation surface by using SAMs and polymers [41-43]. Moreover, a method, which adjusts a dose of irradiation to cause decomposition or photo-polymerization while moving the light shutter, has also been adopted to prepare the gradation surfaces [44-47]. In particular, based on the inherent property of a polymer, the wettability and charge of the surface can be controlled by the gradation of the polymer; these properties are attracting significant attention in advanced research fields [48-52]. The length and graft density of the polymer chains could be easily controlled for the concentrated polymer brush constructed via SI-ATRP. Therefore, it can be expected that microfabricated surfaces can be prepared more precisely by this method compared to other methods [53-54].

In this study, a zwitterionic polymer brush was prepared by surface-initiated atom transfer radical polymerization (SI-ATRP) from the self-assembled monolayer (SAM) of the ATRP initiator having a 2-bromoisobutyryl end group. With UV irradiation at $254 \mathrm{~nm}$, the bromine atom essential for the initiation of ATRP could be selectively cleaved and therefore, by varying the irradiation time, the surface density of the polymer brush could be easily controlled. Since the zwitterionic polymer brush strongly suppressed protein adsorption and cell adhesion, we expected that we could manipulate the protein adsorption and cell adhesiveness onto the originally bio-inert polymer brush introduced to the surface of glass, silicon wafers, and various metal oxides.

Furthermore, by gradation of the irradiation period along the ATRP initiator-modified SAM, the gradation of the zwitterionic polymer brush can be easily realized (Figure 1). Such a 
technique will be highly useful for bio-related applications.

\section{Experimental section}

\subsection{Materials}

1-carboxy- $N, N$-dimethyl- $N$-(2-methacryloyloxyethyl)methanaminium hydroxide inner salt $\left(\mathrm{CMB}, \mathrm{GLBT}^{\circledR}\right.$ ) (Scheme 1(a)) was kindly donated by Osaka Organic Chemical Industries, Osaka, Japan. 3-(2-Bromo-2-isobutyryloxy)propyltriethoxysilane (BPE, Scheme 1(b)) was prepared as described elsewhere [55]. 2,2'-Bipyridine (Bpy, 99.5\%) and copper (I) bromide $(\mathrm{Cu}(\mathrm{I}) \mathrm{Br}, 99.999 \%)$ were purchased from Wako Pure Chemicals Osaka, Japan. $\mathrm{Cu}(\mathrm{I}) \mathrm{Br}$ was purified by stirring in acetic acid overnight and dried after filtration at low pressure. Ethyl 2-bromoisobutyrate (EBiB, 98\%, Scheme 1(c)) and bovine serum albumin (BSA) were purchased from Nacalai Tesque (Kyoto, Japan) and Sigma-Aldrich (Milwaukee, WI, USA), respectively. Toluene (99.5\%, Wako Pure Chemicals) was stirred with concentrated sulfuric acid, followed by washing with saturated aqueous sodium carbonate solution and water. The purified toluene was finally obtained by distillation. Other reagents were commercially available. Milli-Q grade water (<18 M $\Omega . c m)$ was used for preparation of sample solutions.

\subsection{Construction of polymer brush}

\subsubsection{Introduction of ATRP initiator (BPE) (Scheme 2(a))}

A glass substrate $\left(20 \times 26 \mathrm{~mm}^{2}\right)$ was washed by ultrasonication in methanol for $10 \mathrm{~min}$ and rinsed with water before immersing in a piranha solution (sulfuric acid : hydrogen peroxide solution $=7: 3$ ) for $1 \mathrm{~h}$. The glass substrate was further washed with deionized water more than ten times, rinsed with acetone, and dried by $\mathrm{N}_{2}$ gas. The pristine glass substrate was incubated in a toluene solution of BPE $(2 \mathrm{mM})$ overnight in the dark. The BPE-modified substrate was washed with toluene, ultrasonicated in toluene, repeatedly rinsed with methanol 
and acetone, and finally dried by $\mathrm{N}_{2}$ gas.

\subsubsection{Construction of PCMB brush via SI-ATRP (Scheme 2(b))}

CMB (3.50 g, $15.0 \mathrm{mmol}$ ) and ethyl 2-bromoisobutyrate (EBiB, ATRP initiator, $22.2 \mu \mathrm{L}$, $0.15 \mathrm{mmol})$ were dissolved in methanol $(30 \mathrm{~mL})$ and vacuum-degassed with argon 10 times. Thereafter, the mixed solution was sent to the reaction vessel containing 2,2'-bipyridyl (Bpy, $46.9 \mathrm{mg}, 0.30 \mathrm{mmol}), \mathrm{CuBr}(21.5 \mathrm{mg}, 0.15 \mathrm{mmol})$, and the BPE SAM-modified glass substrate through a PTFE tube under an argon atmosphere. The molar ratio was configured to $[\mathrm{CMB}]:[\mathrm{EBiB}]:[\mathrm{CuBr}]:[\mathrm{Bpy}]=100: 1: 1: 2$, and the ATRP reaction was carried out for $48 \mathrm{~h}$ at $30^{\circ} \mathrm{C}$. After the reaction, the PCMB brush-modified substrate was washed with methanol, ultrasonicated in methanol, repeatedly rinsed with methanol, water, and acetone, and finally dried by a flush of $\mathrm{N}_{2}$ gas. The solution of PCMB produced in the liquid phase at the same time was recovered and, after passing through a chelate resin column (IRC748 AmBerlite, Organo Ltd., Tokyo, Japan) in water to remove copper salt, condensed by evaporation. The purified solution containing PCMB was dialyzed against methanol for a week. The PCMB solution was condensed by evaporation, dissolved in water, and finally lyophilized (yield: 2.9 $\mathrm{g}, 83.1 \%)$. The number-averaged molecular weight $\left(M_{\mathrm{n}}\right)$, weight-averaged molecular weight $\left(M_{\mathrm{w}}\right)$, and distribution of molecular weight $\left(M_{\mathrm{w}} / M_{\mathrm{n}}\right)$ of PCMB were determined by gel

permeation chromatography (GPC, Wako beads G-50, Wako Pure Chemicals; mobile phase, 0.1 M NaBr aq. soln.).

\subsection{UV Irradiation of substrates}

\subsubsection{Quantitative irradiation}

The PCMB-modified glass plate was UV-irradiated at $254 \mathrm{~nm}\left(0.135 \mathrm{~mJ} \cdot \mathrm{cm}^{-2} / \mathrm{s}\right.$, MODEL UVGL-58, UVP, USA). The glass substrate was washed with methanol and dried by a flush of $\mathrm{N}_{2}$ gas. 


\subsubsection{Gradation of irradiation}

A UV irradiation system was prepared to continuously change the dose of irradiation (Figure S-1 in Supporting Information). A UV shutter and the BPE-modified substrate were set on an irradiation stage made of a Teflon plate $(43 \mathrm{~mm} \times 43 \mathrm{~mm}$, NICHIAS Corporation, Tokyo, Japan). The shutter of the system can be smoothly moved at a set speed using a stepping motor $\left(0.1 \times 10^{-3} \mathrm{~mm} / \mathrm{s} \sim 0.11 \mathrm{~mm} / \mathrm{s}\right)$. It was expected that a different range of $\mathrm{Br}$ gradation can be formed by moving the UV shutter at different speeds under a certain dose of irradiation. Two modes of sliding-speed were adopted to move the UV shutter for the irradiation (Table S-1 in Supporting Information)

\subsection{Characterization of polymer brush}

\subsubsection{Evaluation of thickness by ellipsometry measurements}

The thickness of the polymer brush (dry state) was evaluated by ellipsometry (Lambda Ace RE-3100, DAINIPPON SCREEN MFG. Co., Ltd). The measurements were performed at a wavelength of $640 \mathrm{~nm}$ while the refractive index of the sample layer was assumed to be 1.49 (refractive index of poly(methyl methacrylate)) [56-57].

\subsubsection{Wettability evaluation of substrate}

The contact angle of a water droplet was measured to evaluate the wettability of the substrate using CA-D (Kyowa Surface Science, Tokyo, Japan). A droplet of deionized water (3-4 $\mu \mathrm{L}$ ) was put in contact with the surface of the dried substrate to determine the contact angle $30 \mathrm{~s}$ after the contact. The measurement was performed 5 times for each sample, and an average value was obtained.

\subsubsection{XPS measurements}


X-ray photoelectron spectroscopy (XPS, ESCALAB 250Xi, Thermo Fisher Scientific, Inc., Waltham, Massachusetts, USA) was used for the evaluation of various elements on the substrate surface. Measurement conditions: detection angle, $90^{\circ} ;$ X-ray source type, monochromated/micro-focused AlK-Alpha; X-ray size, $650 \mu \mathrm{m}$. Analysis of the peak was carried out using Avantage (Ver. 4.84) of Thermo Fisher Scientific Corporation.

\subsection{Protein adsorption}

Protein adsorption on the PCMB brush-modified substrate was measured using a BCA method reported in previous studies $[35,58]$. For the gradated pattern of adsorbed A488-IgG (Alexa Fluor 488 goat anti-rabbit $\operatorname{IgG}$ ), the adsorption of fluorescence-labeled protein was observed on a substrate modified with the PCMB brush. After mounting the A488-IgG solution $(150 \mu \mathrm{L}, 100 \mu \mathrm{g} / \mathrm{mL}$ in PBS $)$ onto the substrate, incubation under a dark box at $25^{\circ} \mathrm{C}$ for $2 \mathrm{~h}$, and rinsing thoroughly with PBS, fluorescence images were observed by a fluorescence microscope (IX71, Olympus Corporation).

\subsection{Cell adhesion}

Adhesion of NIH3T3 cells was observed on the PCMB brush-modified substrate and the number of cells was counted. Experimental procedures were the same as those reported elsewhere [35, 58].

\section{Results and discussion}

\subsection{Decomposition of ATRP initiator by UV irradiation}

The ATRP initiator, BPE, was easily introduced to a glass surface as indicated by the drastic increase in contact angle (from $8.2^{\circ}$ of bare glass to $69.4^{\circ}$ after incubation with BPE). By subjecting the BPE-modified silicon wafer to UV irradiation, the XPS signal for bromine $\left(\mathrm{Br}_{3 \mathrm{~d}}\right.$, ca. $\left.71 \mathrm{eV}\right)$ was observed to decrease (Figure 2(a)), indicating the scission of the $\mathrm{C}-\mathrm{Br}$ 
bond, whereas the signals for other elements did not change significantly (Figure S-2 in Supporting Information). Therefore, UV irradiation easily reduced the surface density of BPE on the substrate. Consequently, it can be expected that the density of polymer chains could be simply modulated.

In previous studies, UV light (180-190 nm) was used to decompose a part of SI-ATRP initiator-modified surface for the construction of patterned polymer brushes [15, 40]. Therefore, we tried to irradiate at $184 \mathrm{~nm}$ wavelength in a preset experiment. However, it was shown that not only the $\mathrm{C}-\mathrm{Br}$ bond but also all bonds such as $\mathrm{C}-\mathrm{O}$ and $\mathrm{C}-\mathrm{C}$ were decomposed. This is because the graft density of the polymer brush and the density of adhered cells could not be controlled precisely. Thus, a UV light at $254 \mathrm{~nm}$ wavelength (with a comparatively lower energy) was adopted to decompose the $\mathrm{C}$-Br bond selectively.

\subsection{Construction of PCMB brush}

PCMB brushes could be easily constructed by SI-ATRP on both BPE-modified glass and silicon wafer. With the introduction of the PCMB brush, the contact angle of the glass substrate was drastically decreased from $69.4^{\circ}$ (BPE-SAM) to $12.5^{\circ}$ (PCMB) (Figure S-3 in Supporting Information), which is in agreement with previous results [19].

Meanwhile, it was reported that the $M_{\mathrm{n}}$ and $M_{\mathrm{w}} / M_{\mathrm{n}}$ values for the grafted and free polystyrene subjected to ATRP at the same time were nearly equal [59-60]. Assuming the same tendency, i.e. the degree of polymerization of the PCMB brush is the same as that of PCMB produced in the solution phase at the same time, the degree of polymerization of the PCMB brush was estimated to be 125 (close to the target degree of polymerization, 100) using GPC. The $M_{\mathrm{n}}$ and $M_{\mathrm{w}} / M_{\mathrm{n}}$ values of the PCMB brush were estimated to be $2.9 \times 10^{4}$ and 1.48 , respectively, which showed the relatively narrow molecular weight distribution of this polymer.

The thickness of the PCMB brush on the silicon wafer was estimated by ellipsometry and 
the surface density of the brush $(\sigma)$ was determined using equation (1).

$$
\sigma=\rho d N_{\mathrm{A}} \times 10^{-21} / M_{\mathrm{n}}
$$

where $\sigma$ is the graft density (chains $\left./ \mathrm{nm}^{2}\right), \rho$ is the polymer density $\left(\mathrm{g} / \mathrm{cm}^{3}\right), N_{\mathrm{A}}$ is Avogadro's number, $d$ is the thickness of the polymer brush (nm), and $M_{\mathrm{n}}$ is the number-averaged molar mass of bulk polymer. The $\rho$ value for poly(methacryloyloxyethyl phosphorylcholine) (1.30 $\mathrm{g} / \mathrm{cm}^{3}$ ) available in the literature [15] was used to calculate the surface density of the PCMB brush.

When the graft density is higher than 0.1 chains $/ \mathrm{nm}^{2}$, the brush is referred to as a "concentrated polymer brush" [15]. The thickness of the PCMB brush prepared on the BPE SAM in this study was estimated to be $8.1 \mathrm{~nm}$, and the graft density without UV irradiation was determined to be 0.21 chains $/ \mathrm{nm}^{2}$, which means that a concentrated PCMB brush was constructed (Figure S-4 in Supporting Information).

\subsection{PCMB brush on UV-irradiated BPE SAMs}

XPS data indicated that, as a result of the UV irradiation of BPE SAM, the signal intensity of bromine atoms was gradually decreased and at $3000 \mathrm{~mJ} / \mathrm{cm}^{2}$, almost completely diminished (Figure 2(a)). Therefore, the thickness and surface density of the PCMB brush were observed to decrease by UV irradiation, as expected (Figure S-4 in Supporting Information). Correspondingly, the water contact angle on the PCMB brush surface was largely increased with exposure time up to about $2000 \mathrm{~mJ} / \mathrm{cm}^{2}$ (Figure S-3 in Supporting Information). In the case of a concentrated zwitterionic brush, the large hydrophilicity of the brush-modified surface has been reported $[19,28]$, which means that the initiator layer did not affect the surface properties of the brush when the thickness of the brush was larger than 2.5$5 \mathrm{~nm}[60]$. The thickness of the PCMB brush was estimated to be 3.0 and $1.9 \mathrm{~nm}$ at 1000 $\mathrm{mJ} / \mathrm{cm}^{-2}$ and $2000 \mathrm{~mJ} / \mathrm{cm}^{-2}$ of UV irradiation, respectively, on the BPE SAM.

In addition, we tried to construct a gradated PCMB brush using a stepping motor-driven 
UV shutter smoothly moving above the stage of both the BPE-modified glass and silicon wafer at a constant speed (Table S-1 in Supporting Information). The XPS data along the direction of the movement of the UV shutter indicated that the signal intensity of bromine elements $\left(\mathrm{Br}_{3 \mathrm{~d}}\right.$, ca. $\left.71 \mathrm{eV}\right)$ at the end of the ATRP initiator linearly decreased, indicating the gradation of the surface density of $\mathrm{Br}$ along the substrate (Figure 2(b)). Changes were hardly observed in the other elements $\left(\mathrm{Si}_{2 \mathrm{p}}\right.$, ca. $100 \mathrm{eV} ; \mathrm{C}_{1 \mathrm{~s}}$, ca. $\left.286 \mathrm{eV}\right)$ after UV irradiation (Figure S-5(a) in Supporting Information). Furthermore, an increase in the peak of nitrogen elements $\left(\mathrm{N}_{1 \mathrm{~s}}\right.$, ca. $\left.402 \mathrm{eV}\right)$ ascribable to the $\mathrm{CMB}$ unit was observed along the moving direction of the UV shutter on the PCMB brush surface constructed above the BPE SAM-modified substrate surface that had been subjected to continuous irradiation. Moreover, Figures 3(a) and (b) showed that it was possible to prepare a gradated PCMB brush corresponding to the setting range of $12.0 \mathrm{~mm}$ (Mode 1) and $4.81 \mathrm{~mm}$ (Mode 2) (Table S-1 in Supporting Information). In addition, the variations of the peak $\left(\mathrm{Si}_{2 \mathrm{p}}, \mathrm{C}_{1 \mathrm{~s}}\right)$ in the total spectra except $\mathrm{N}_{1 \mathrm{~s}}$ corresponded to the setting range of gradation (Figure $\mathbf{S}-\mathbf{5}(\mathbf{b})$ and (c) in Supporting Information).

\subsection{Gradation in protein adsorption and cell adhesion to the PCMB brush}

The XPS data suggest that the surface density of protein adsorption and cell adhesion to the surface of the PCMB brush can be varied with irradiation time. Actually, the amount of proteins adsorbed was increased with an increase in the dose of UV irradiation from a region between $500-1000 \mathrm{~mJ} / \mathrm{cm}^{2}$. In the same region, the graft density of the PCMB brush was 0.12-0.08 chains $/ \mathrm{nm}^{2}$ (Figure 4(a)). Thus, it was speculated that BSA molecules were hardly adsorbed to a concentrated PCMB brush-modified surface when the graft density was above 0.1 chains $/ \mathrm{nm}^{2}$, whereas adsorption occurred below 0.1 chains $/ \mathrm{nm}^{2}$. For concentrated polymer brushes, various unique properties such as high elasticity, ultra-low friction, and size exclusion effects have been reported [61-64]. 
In a similar manner, the number of NIH3T3 cells adhered to the substrate was increased with an increase in the dose of UV irradiation above $1500 \mathrm{~mJ} / \mathrm{cm}^{2}$ (Figure $4(\mathbf{b})$ ). It has often been pointed out that cells tend to adhere via the anchor proteins adsorbed to the solid substrate [65]. At a UV irradiation of $1500 \mathrm{~mJ} / \mathrm{cm}^{2}$, the amount of BSA adsorbed was approximately $40 \mathrm{ng} / \mathrm{cm}^{2}$. Therefore, it could be expected that protein adsorption needs to exceed approximately $40 \mathrm{ng} / \mathrm{cm}^{2}$ for cells to adhere to the PCMB brush-modified surface.

The scaffold proteins might adsorb to the area where the surface density of the PCMB brush was much smaller than that in the non-irradiated area, which would result in the preferential adhesion of NIH3T3 cells (Figure S-6 in Supporting Information).

We further examined the possibility of gradation in the amount of adsorbed proteins and number of adhered cells controlled by the irradiation period of UV light. The XPS data along the direction of the movement of the UV shutter indicated that the intensity of Br atoms at the end of the ATRP initiator linearly increased. In other words, the gradation of $\mathrm{Br}$ along the substrate was observed (Figure 2(b)). Consequently, the gradation of the surface polymer brush density could be realized, which resulted in the gradation of the densities of adsorbed proteins and adhered cells.

In fact, it was found that the adsorption of fluorescent proteins decreased gradually from the starting point $(0 \mathrm{~mm})$ of irradiation on the gradated PCMB brush surface that was prepared under the conditions of Mode $1(12.0 \mathrm{~mm})$ (Figure 5(a)). The adhesion of NIH3T3 cells showed a similar tendency (Figure 5(b)). The number of adherent cells observed showed that adhesion no longer appeared at the region at around $7.4 \mathrm{~mm}$ (Figure 6). On the other hand, changes in cell adhesion on the gradated PCMB brush surface that had been prepared under the conditions of Mode $2(4.81 \mathrm{~mm})$ showed that adhesion no longer appeared at around $3.0 \mathrm{~mm}$ (Figure S-7 in Supporting Information).

In addition, when the UV irradiation dose (Q) was calculated using equation (2) and irradiation conditions (Table S-1 in Supporting Information) at a position (d) (Mode 1: 7.4 
$\mathrm{mm}$ and Mode 2: $3.0 \mathrm{~mm}$ ) where cell adhesion no longer appeared, quite similar results of irradiation dose $\left(1145 \mathrm{~mJ} / \mathrm{cm}^{2}\right.$ and $1128 \mathrm{~mJ} / \mathrm{cm}^{2}$, respectively) were obtained.

$$
\mathrm{Q}=\left(d_{0}-d\right) w / v
$$

where $d_{0}$ is the moving distance of the UV shutter $(\mathrm{mm}), w$ is the strength of UV irradiation $\left(\mathrm{mJ} \cdot \mathrm{cm}^{-2} / \mathrm{s}\right)$, and $v$ is the speed of sliding the UV shutter $\left(\mathrm{mm} \cdot \mathrm{s}^{-1}\right)$. Therefore, using this method, the range could provide variously gradated materials, and high reproducibility and controllability were verified.

Thus, by controlling the changing rate of the dose of UV $(254 \mathrm{~nm})$ irradiation along the surface of the initiator SAM-modified substrate, the construction of gradated polymer brushes could be realized. Moreover, there was no need for complicated procedures and sophisticated devices in the polymerization. Moreover, we do not need to worry about the disadvantageous effect of UV on the polymer brush because the process of UV irradiation was only administered to the initiator-modified substrate and selectively decomposed the active site of SI-ATRP. The proposed simple method to precisely control the surface density of bio-inert polymer brushes is anticipated not only in scientific research but also in industrial applications.

\section{Conclusion}

By UV irradiation, a bromine atom at the end of an ATRP initiator SAM introduced to the surface of glass and silicon wafer could be easily removed, and the surface density of PCMB brushes constructed from the radical produced by the dissociation of the $\mathrm{C}$-Br bond could be controlled by the regulation of irradiation time. We were able to correlate graft density of polymer brushes with protein adsorption or cell adhesion using this technique. Furthermore, because the irradiation using $254 \mathrm{~nm}$ hardly affected other bonds, it can be applied to not only solid materials such as glass and metal but also polymer/plastic-based materials that can be 
easily deteriorated by intense UV light (<200 nm). Using a motor-driven UV shutter, the surface density of cells adhered to the brush could be easily gradated along the direction of the shutter movement, suggesting the gradation of the amount of adsorbed proteins to which cells adhered.

\section{Acknowledgements}

This research was supported by a Grant-in-Aid for Scientific Research (26288100, 15H05353) from the Japan Society for the Promotion of Science (JSPS) and a Grant-in-Aid for Scientific Research on Innovative Areas (20106007) from the Ministry of Education, Culture, Sports, Science and Technology (MEXT), Japan. T. N-H is grateful to Japan Science and Technology Agency (JST) for the tenure-track program. We are indebted to Osaka Organic Chemical Industry for the donation of CMB. We would like to thank Mr. Hirokazu Makino for his technical assistances. 


\section{References}

[1] S. Edmondson, V.L. Osborne, W.T.S. Huck, Chem. Soc. Rev. 33 (2004) 14.

[2] F. Zhou, W. Liu, T. Xu, S. Liu, M. Chen, J. Liu, J. Appl. Polym. Sci. 92 (2004) 1695.

[3] D. Sethi, A. Kumar, K.C. Gupta, P. Kumar, Bioconjugate. Chem. 19 (2008) 2136.

[4] H. Kitano, A. Hayashi, H. Takakura, H. Suzuki, N. Kanayama, Y. Saruwatari, Langmuir 25 (2009) 9361.

[5] H. Suzuki, L. Li, T. Nakaji-Hirabayashi, H. Kitano, K. Ohno, K. Matsuoka, Y. Saruwatari, Colloids Surf. B 94 (2012) 107.

[6] J.S. Wang, K. Matyjaszewski, J. Am. Chem. Soc. 117 (1995) 5614.

[7] K. Matyjaszewski, J. Xia, Chem. Rev. 101 (2001) 2921.

[8] M. Kato, M. Kamigaito, M. Sawamoto, T. Higashimura, Macromolecules 28 (1995) 1721.

[9] M. Kamigaito, T. Ando, M. Sawamoto, Chem. Rev. 101 (2001) 3689.

[10] Y. Mitsukami, M.S. Donovan, A.B. Lowe, C.L. McCormick, Macromolecules 34 (2001) 2248 .

[11] C.L. McCormick, A.B. Lowe, Acc. Chem. Res. 37 (2004) 312.

[12] M. Husseman, E.E. Malmstrom, M. McNamara, M. Mate, D. Mecerreyes, D.G. Benoit, J.L. Hedrick, P. Mansky, E. Huang, T.P. Russell, C.J. Hawker, Macromolecules 32 (1999) 1424.

[13] C.J. Hawker, A.W. Bosman, E. Harth, Chem. Rev. 101 (2001) 3661.

[14] W. Feng, J.L. Brash, S. Zhu, Biomaterials 27 (2006) 847.

[15] R. Iwata, P. Suk-In, V.P. Hoven, A. Takahara, K. Akiyoshi, Y. Iwasaki, Biomacromolecules 5 (2004) 2308.

[16] W. Feng, S. Zhu, K. Ishihara, J.L. Brash, Langmuir 21 (2005) 5980.

[17] A.L. Lewis, Colloids Surf. B 18 (2000) 261.

[18] T. Kondo, M. Gemmei-Ide, H. Kitano, K. Ohno, H. Noguchi, K. Uosaki, Colloids Surf. B $91(2012) 215$. 
[19] T. Kondo, K. Nomura, M. Murou, M. Gemmei-Ide, H. Kitano, H. Noguchi, K. Uosaki, K. Ohno, Y. Saruwatari, Colloids Surf. B 100 (2012) 126.

[20] T. Kondo, K. Nomura, M. Gemmei-Ide, H. Kitano, H. Noguchi, K. Uosaki, Y. Saruwatari, Colloids Surf. B 113 (2014) 361.

[21] H. Kitano, Polymer Journal DOI:10.1038/pj.2015.70

[22] Z. Zhang, A.J. Morse, S.P. Armes, A.L. Lewis, M. Geoghegan, G.J. Leggett, Langmuir $29(2013) 10684$.

[23] Z. Zhang, A.J. Morse, S.P. Armes, A.L. Lewis, M. Geoghegan, G.J. Leggett, Langmuir $27(2011) 2514$

[24] A.J. Morse, S. Edmondson, D. Dupin, S.P. Armes, Z. Zhang, G.J. Leggett, R.L.

Thompson, A.L. Lewis, Soft Matter 6 (2010) 1571.

[25] H. Kitano, T. Mori, S. Tada, Y. Takeuchi, M. Gemmei-Ide, M. Tanaka, Macromol. Biosci. 5 (2005) 314.

[26] H. Kitano, S. Tada, T. Mori, K. Takaha, M. Gemmei-Ide, M. Tanaka, M. Fukuda, Y. Yokoyama, Langmuir 21 (2005) 11932.

[27] K. Ishihara, Technol. Adv. Mater. 1 (2000) 131.

[28] H. Kitano, H. Suzuki, K. Matsuura, K. Ohno, Langmuir 26 (2010) 6767.

[29] H. Kitano, K. Tokuwa, H. Ueno, L. Li, Y. Saruwatari, Colloid. Polym. Sci. 293 (2015) 2931

[30] H. Suzuki, M. Murou, H. Kitano, K. Ohno, Y. Saruwatari, Colloids Surf. B 84 (2011) 111.

[31] M. Murou, H. Kitano, M. Fujita, M. Maeda, Y. Saruwatari, J. Colloid Interface Sci. 390 (2013) 47.

[32] K. Matsuura, K. Ohno, S. Kagaya, H. Kitano, Macromol. Chem. Phys. 208 (2007) 862.

[33] H. Kitano, H. Suzuki, T. Kondo, K. Sasaki, S. Iwanaga, M. Nakamura, K. Ohno, Y. Saruwatari, Macromol. Biosci. 11 (2011) 557. 
[34] H. Kitano, T. Kondo, T. Kamada, S. Iwanaga, M. Nakamura, K. Ohno, Colloids Surf. B $88(2011) 455$.

[35] T. Kamada, Y. Yamazawa, T. Nakaji-Hirabayashi, H. Kitano, Y. Usui, Y. Hiroi, T. Kishioka, Colloids Surf. B 123 (2014) 878.

[36] S.A. Ahmad, G.J. Legett, A. Hucknall, A. Chilkoti, Biointerphases 6 (2011) 8.

[37] J. Wu, Z. Mao, H. Tan, L. Han, T. Ren, C. Gao, Interface Focus 2 (2012) 337.

[38] S.E. Kim, E.C. Harker, A.C.D. Leon, R.C. Advincula, J.K. Pokorski, Biomacromolecules $16(2015) 860$.

[39] S.T. Plummer, Q. Wang, P.W. Bohn, R. Stockton, M.A. Schwartz, Langmuir 19 (2003) 7528.

[40] S.B. Kennedy, N.R. Washburn, C.G. Simon, E.J. Amis, Biomaterials 27 (2006) 3817.

[41] H. Elwing, S. Welin, A. Askendal, U. Nilsson, I. Lundströ m, J Colloid Interface Sci 119 (1987) 203.

[42] S. Morgenthaler, C. Zink, N.D. Spencer, Soft Matter 4 (2008) 419.

[43] M.K. Chaudhury, G.M. Whitesides, Science 256 (1992) 1539.

[44] Y. Ito, M, Heydari, A. Hashimoto, T. Konno, A. Hirasawa, S. Hori, K. Kurita, A.

Nakajima, Langmuir 23 (2007) 1845.

[45] A. Larsson, B. Liedberg, Langmuir 23 (2007) 11319.

[46] B.P. Harris, A.T. Metters, Macromolecules 39 (2006) 2764.

[47] T. Ekblad, O. Andersson, F.I. Tai, T. Ederth, B. Liedberg, Langmuir 25 (2009) 3755

[48] Y. Iwasaki, K. Ishihara, N. Nakabayashi, G. Khang, J.H. Jeon, J.W. Lee, H.B. Lee, J Biomater Sci, Polym Edn 9 (1998) 801.

[49] Y. Iwasaki, S. Sawada, N. Nakabayashi, G. Khang, H.B. Lee, K. Ishihara, Biomaterials $20(1999) 2185$.

[50] L. Ionov, N. Houbenov, A. Sidorenko, M. Stamm, I. Luzinov, S. Minko, Langmuir 20 (2004) 9916. 
[51] L. Ionov, M. Stamm, S. Diez, Nano Letters 5 (2005) 1910.

[52] N.D. Gallant, K.A. Lavery, E.J. Amis, M.L. Becker, Adv. Mater. 19 (2007) 965

[53] M. Gosecka, J. Pietrasik, P. Decorse, B. Glebocki, M.M. Chehimi, S. Slomkowski, T. Basinska, Langmuir 31 (2015) 4853.

[54] N. Shida, Y. Koizumi, H. Nishiyama, I. Tomita, S. Inagi, Angew. Chem. Int. Ed 54: (2015) 3922.

[55] K. Ohno, T. Akashi, Y. Huang, Y. Tsujii, Macromolecules 43 (2010) 8805.

[56] K. Ohno, T. Morinaga, K. Koh, Y. Tsujii, T. Fukuda, Macromolecules 38 (2005) 2137.

[57] J. Brandrup, E.H. Immergut, E.A. Grulke, A. Abe, D.R. Bloch, Polymer Handbook-4th Edition (2003) Wiley-Interscience.

[58] K. Nomura, S. Mikuni, T. Nakaji-Hirabayashi, M. Gemmei-Ide, H. Kitano, H. Noguchi, K. Uosaki, Colloids Surf. B 135 (2015) 267.

[59] K. Ohno, K. Koh, Y. Tsujii, T. Fukuda, Macromolecules 35 (2002) 8989.

[60] Y. Inoue, K. Ishihara, Colloids Surf. B 81 (2010) 350.

[61] Y. Tsujii, M. Ejaz, K. Sato, A. Goto, T. Fukuda, Macromolecules 34 (2001) 8872.

[62] C. Xue, N. Yonet-Tanyeri, N. Brouette, M. Sferrazza, P.V. Braun, D.E. Leckband, Langmuir 27 (2011) 8810.

[63] Y. Zou, N.A.A. Rossi, J.N. Kizhakkedathu, D.E. Brooks, Macromolecules 42 (2009) 4817.

[64] G. Rossi, I.G. Elliott, T. Ala-Nissila, R. Faller, Macromolecules 45 (2012) 563.

[65] C. Yoshikawa, A. Goto, Y. Tsujii, T. Fukuda, T. Kimura, K. Yamamoto, A. Kishida, Macromolecules 39 (2006) 2284. 


\section{Figure Captions}

Figure 1. Schematic illustration of protein adsorption and cell adhesion to the gradated polymer brushes prepared after UV irradiation of BPE SAMs.

Figure 2. (a) Bromine signal of each BPE SAM at various irradiation doses of UV light at $254 \mathrm{~nm}$ at $100 \mathrm{~mJ} / \mathrm{cm}^{2}$ (dotted line), $500 \mathrm{~mJ} / \mathrm{cm}^{2}$ (dotted-chain line), $1000 \mathrm{~mJ} / \mathrm{cm}^{2}$ (dashed line), $2000 \mathrm{~mJ} / \mathrm{cm}^{2}$ (long-dashed line), and $3000 \mathrm{~mJ} / \mathrm{cm}^{2}$ (solid line). (b) XPS line scans of $\mathrm{Br}_{3 \mathrm{~d}}$ area of "Mode 1" plates of BPE SAMs.

Figure 3. XPS line scans of $\mathrm{N}_{1 \mathrm{~s}}$ area of (a) "Mode 1" and (b) "Mode 2" plates of PCMB brushes.

Figure 4. (a) Correlation between amount of adsorbed BSA (०) and graft density ( $\square$ ) of the PCMB brush surfaces upon irradiation of various doses at $254 \mathrm{~nm}$ on BPE SAM. (Dashed line: BSA adsorption to BPE SAM); (b) Correlation between cell density ( $\mathrm{O}$ ) and graft density ( $\square$ ) of the PCMB brush on BPE SAM with doses of UV irradiation (254 nm). (Dashed line: Cell density of BPE). The data are shown as mean value \pm standard deviation for three independent samples.

Figure 5. (a) Fluorescence images of A488-IgG adsorbed onto the gradated PCMB brushes; (b) Phase-contrast and fluorescence microscopic images (green: Calcein-AM; blue: Hoechst 33342 ) of NIH3T3 cells cultured for 24 h onto gradated PCMB brushes.

Figure 6. The density of $3 \mathrm{~T} 3$ cells adhered onto the gradated PCMB brushes at various distances from the starting point of irradiation. The data are shown as mean value \pm standard deviation for three independent samples.

Scheme 1. Chemical structures of (a)

1-carboxy- $N, N$-dimethyl- $N$-(2-methacryloyloxyethyl)methanaminium hydroxide inner salt (CMB, GLBT $\left.{ }^{\circledR}\right)$, (b) 3-(2-bromo-2-isobutyryloxy)propyltriethoxysilane (BPE), and (c) Ethyl 2-bromoisobutyrate (EBiB).

Scheme 2. Preparation of (a) BPE SAM by a silane-coupling reaction and (b) PCMB brush-modified substrate via SI-ATRP, and accompanying polymerization of free PCMB. 


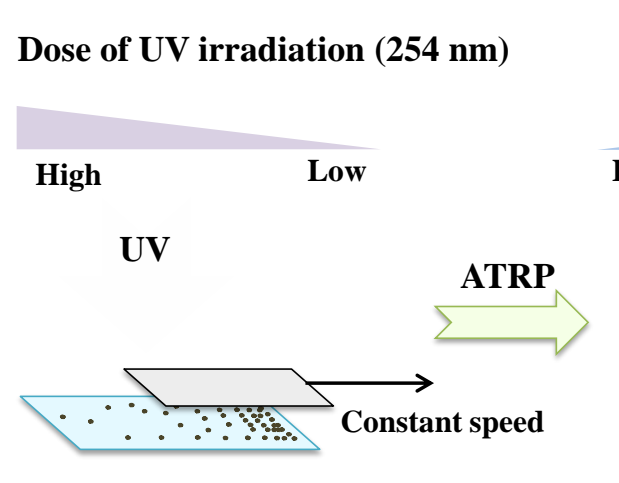

BPE SAMs
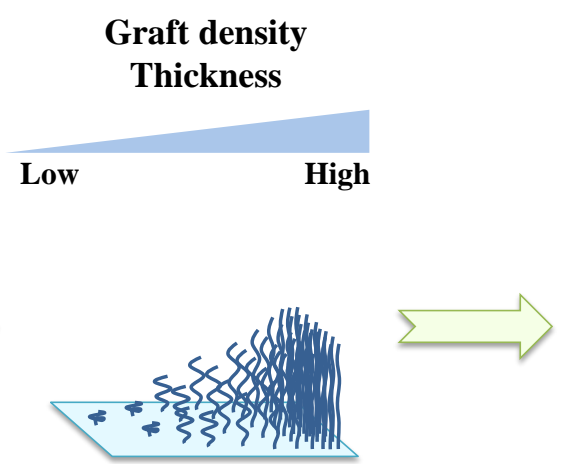

Gradated PCMB Brushes
Protein Adsorption

Cell Adhesion
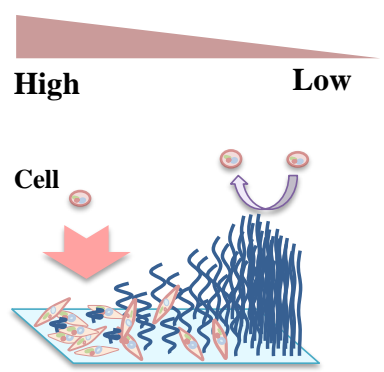

Figure 1. Schematic illustration of protein adsorption and cell adhesion to the gradated polymer brushes prepared after UV irradiation of BPE SAMs. 
(a)

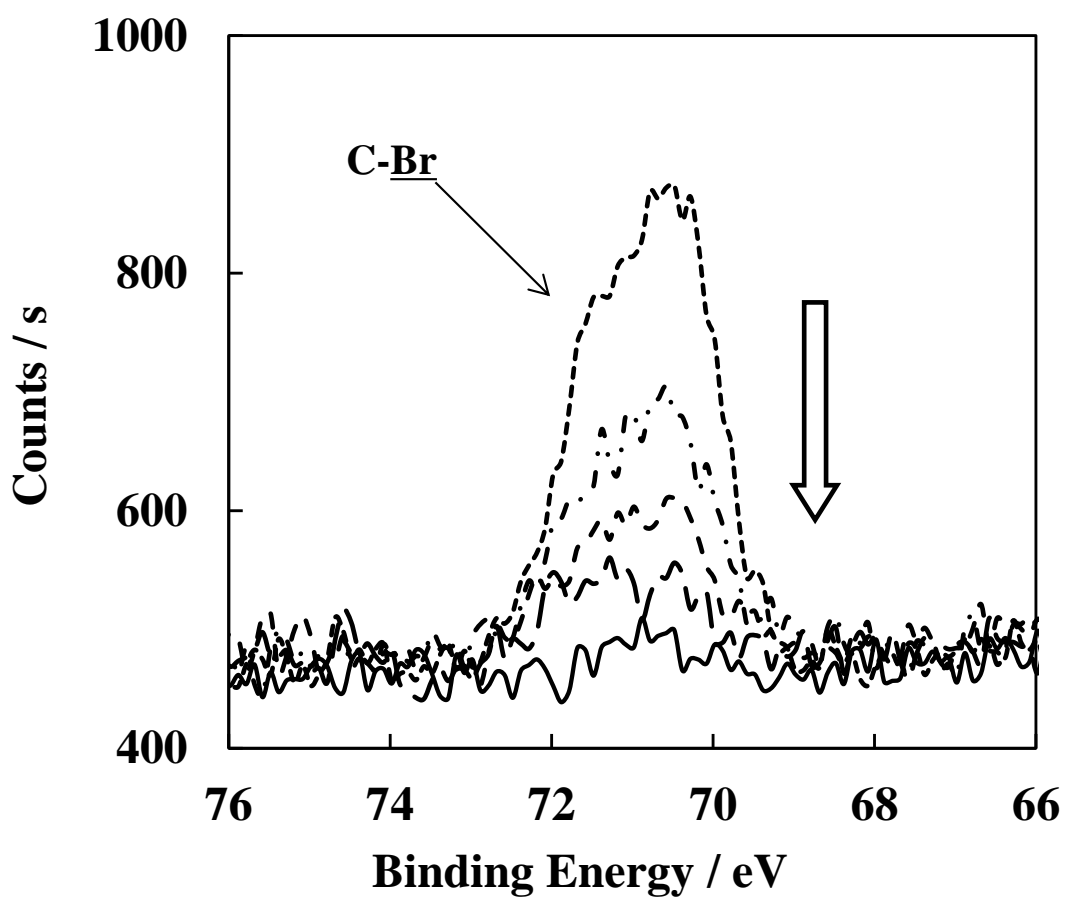

(b)

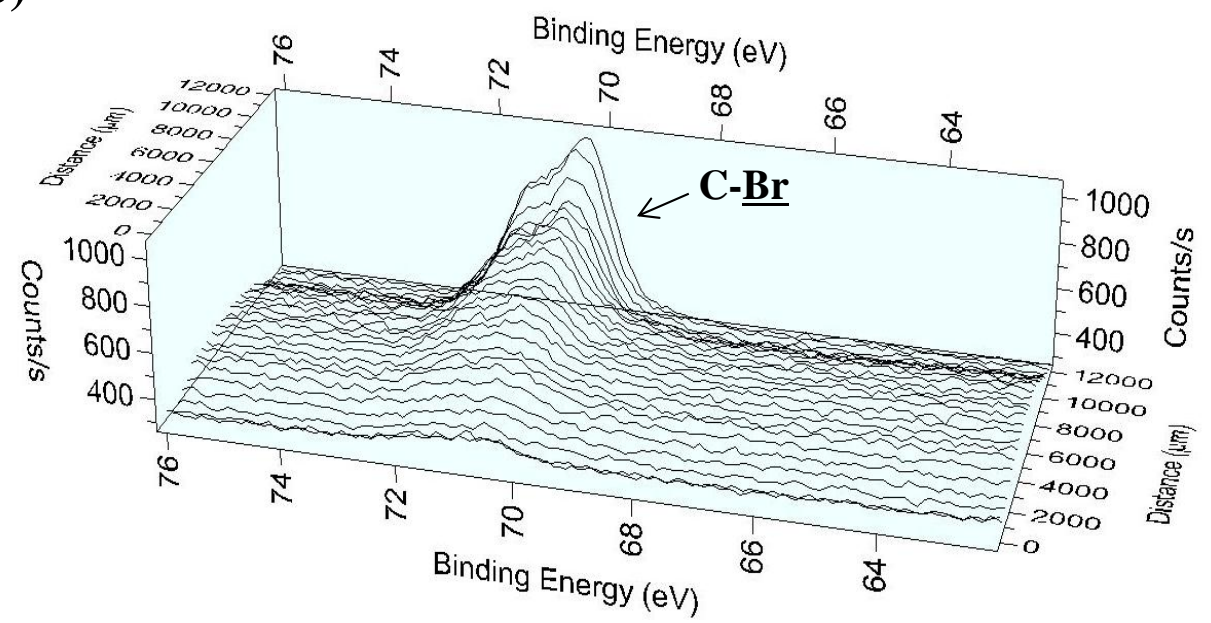

Figure 2. (a) Bromine signal of each BPE SAM at various irradiation doses of UV light at $254 \mathrm{~nm}$ at $100 \mathrm{~mJ} / \mathrm{cm}^{2}$ (dotted line), $500 \mathrm{~mJ} / \mathrm{cm}^{2}$ (dotted-chain line), $1000 \mathrm{~mJ} / \mathrm{cm}^{2}$ (dashed line), $2000 \mathrm{~mJ} / \mathrm{cm}^{2}$ (long-dashed line), and $3000 \mathrm{~mJ} / \mathrm{cm}^{2}$ (solid line). (b) XPS line scans of $\mathrm{Br}_{3 \mathrm{~d}}$ area of "Mode 1" plates of BPE SAMs. 

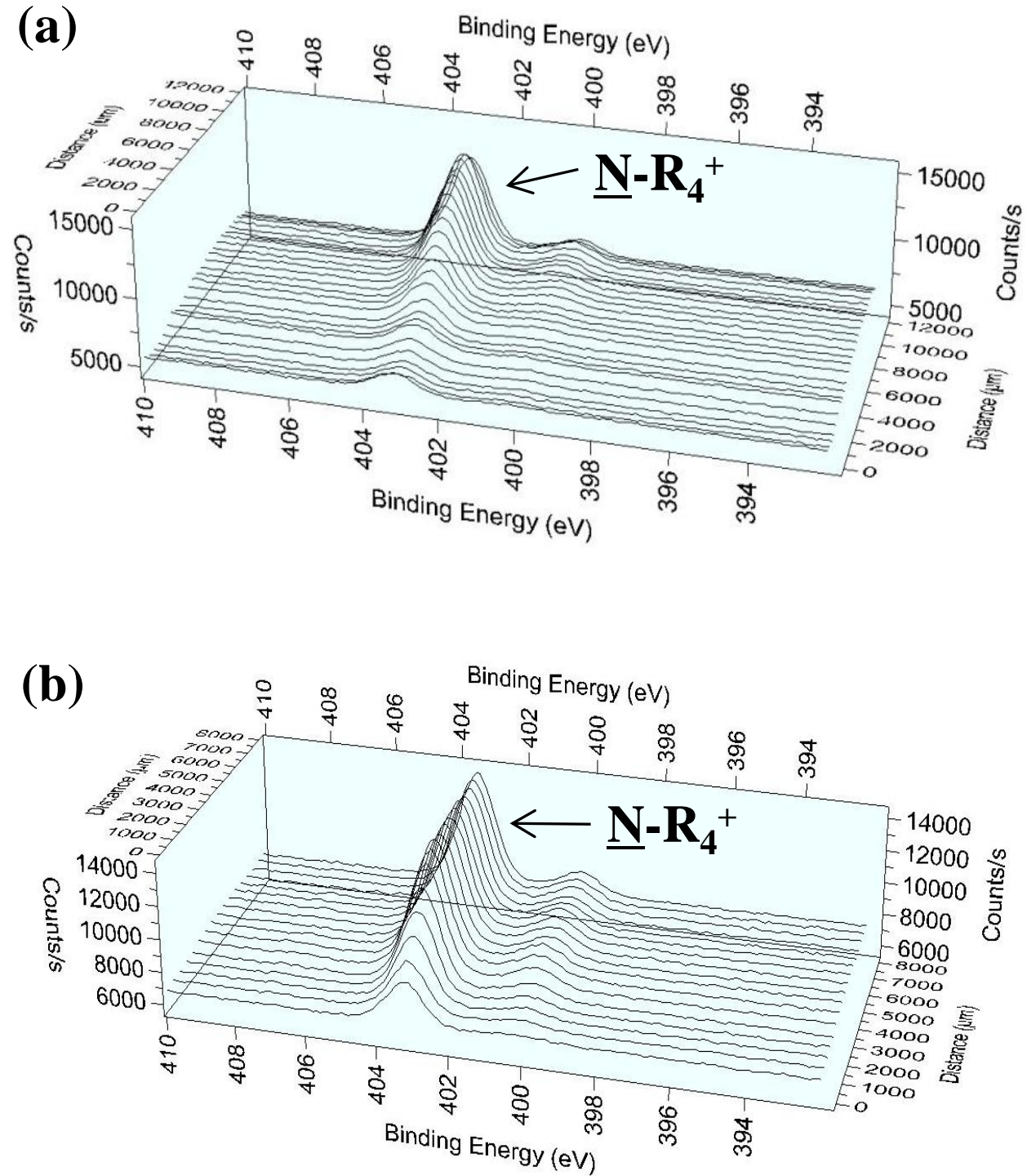

Figure 3. XPS line scans of $\mathrm{N}_{1 \mathrm{~s}}$ area of (a) "Mode 1" and (b) "Mode 2" plates of PCMB brushes. 
(a)

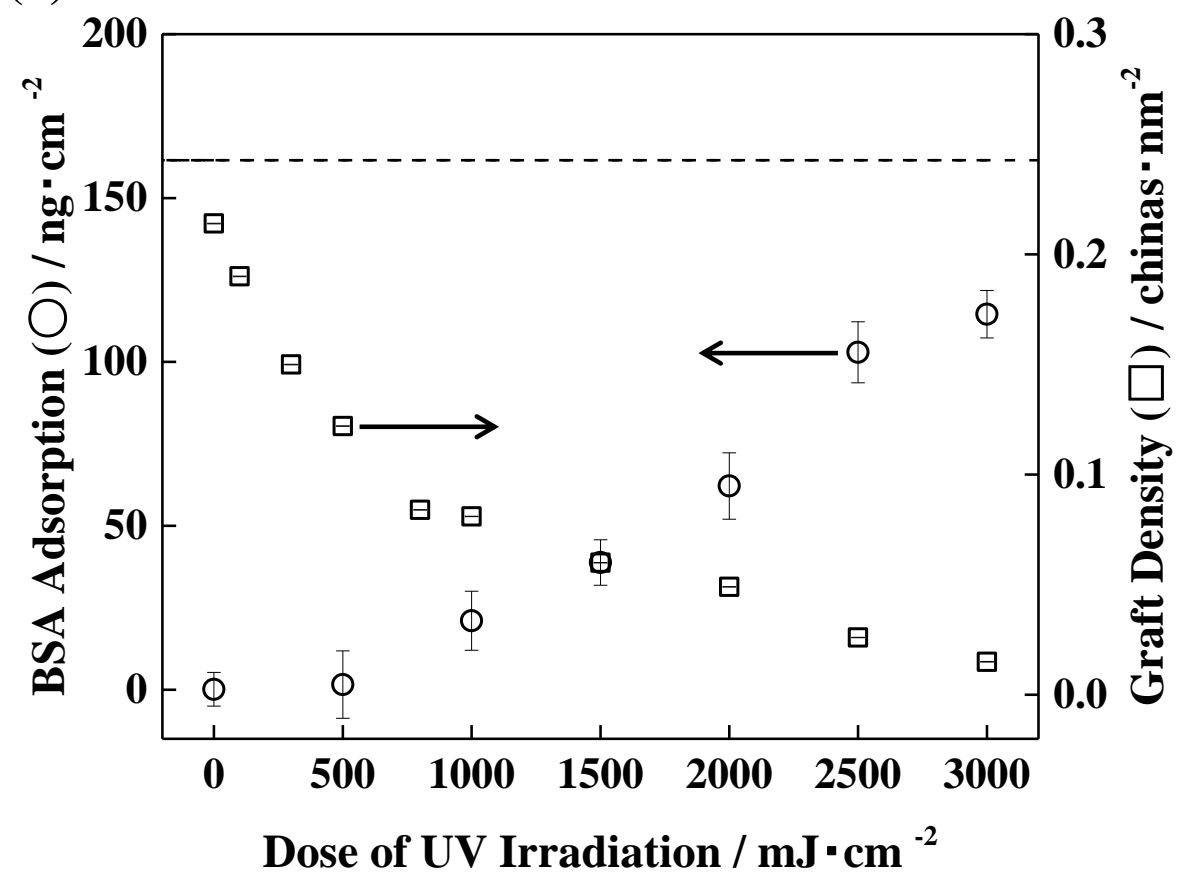

(b)

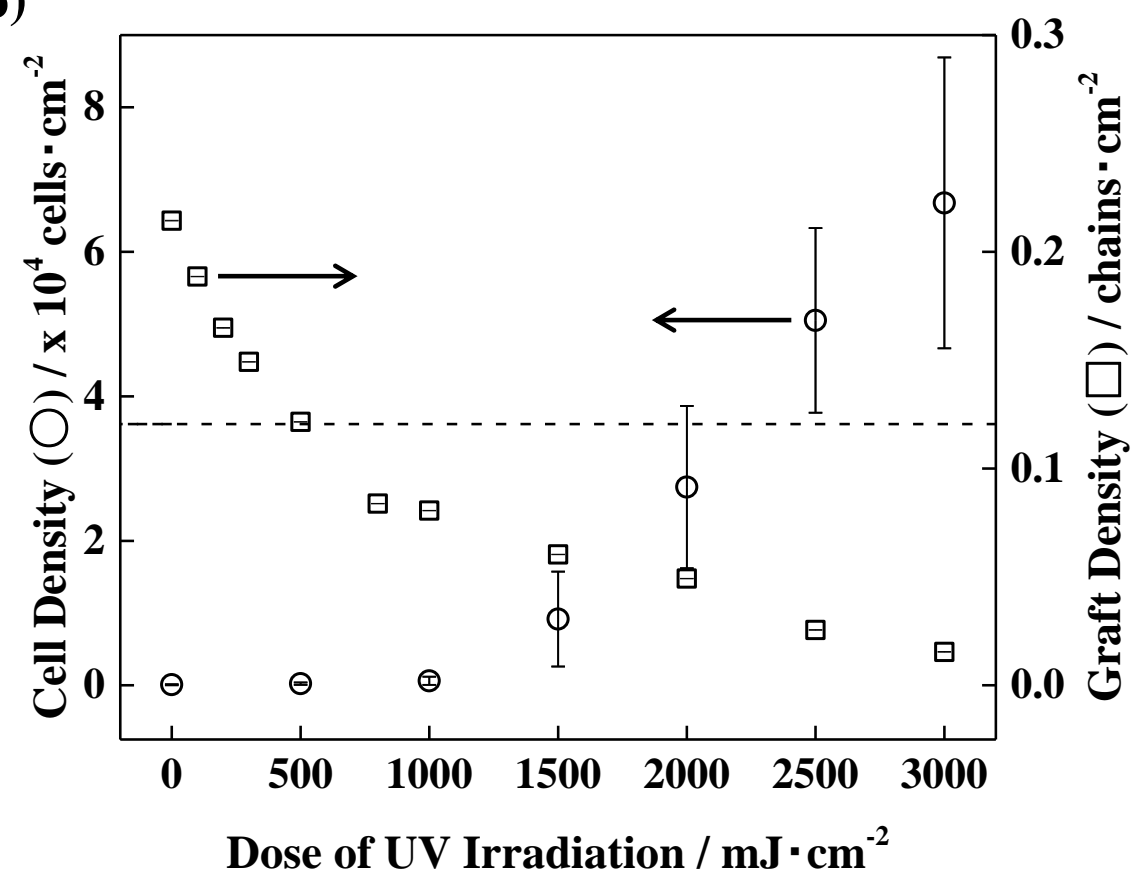

Figure 4. (a) Correlation between amount of adsorbed BSA ( $($ ) and graft density ( $\square$ ) of the PCMB brush surfaces upon irradiation of various doses at $254 \mathrm{~nm}$ on BPE SAM. (Dashed line: BSA adsorption to BPE SAM); (b) Correlation between cell density ( 0 ) and graft density (口) of the PCMB brush on BPE SAM with doses of UV irradiation $(254 \mathrm{~nm})$. (Dashed line: Cell density of BPE). The data are shown as mean value \pm standard deviation for three independent samples. 
(a)

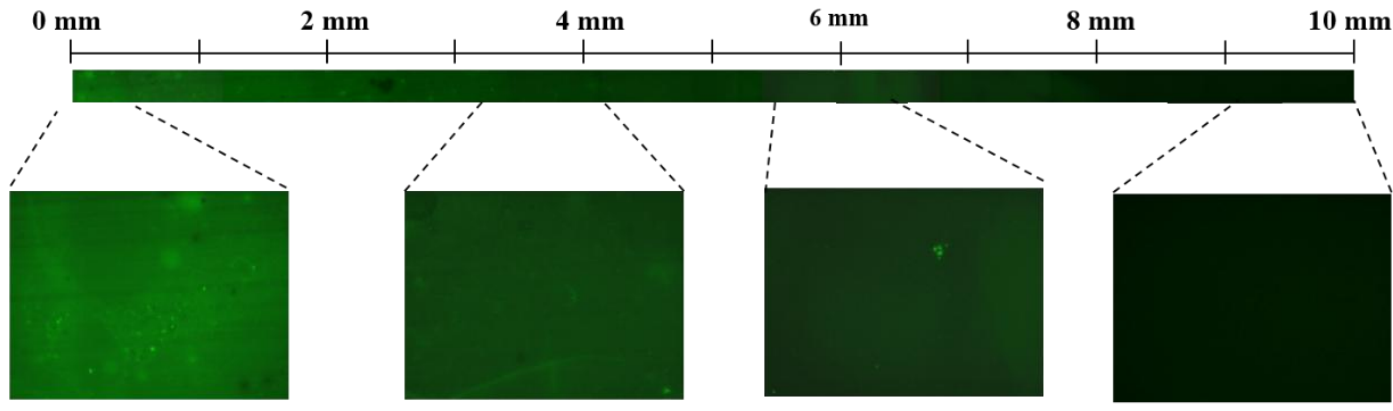

(b)

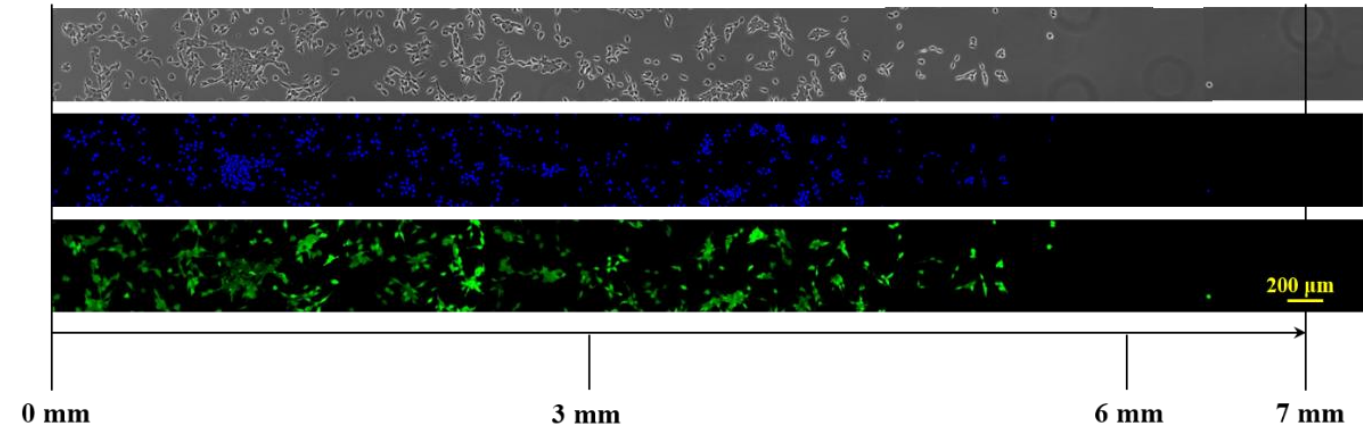

Starting Point

Figure 5. (a) Fluorescence images of A488-IgG adsorbed onto the gradated PCMB brushes; (b) Phase-contrast and fluorescence microscopic images (green: Calcein-AM; blue: Hoechst 33342) of NIH3T3 cells cultured for 24 h onto gradated PCMB brushes. 


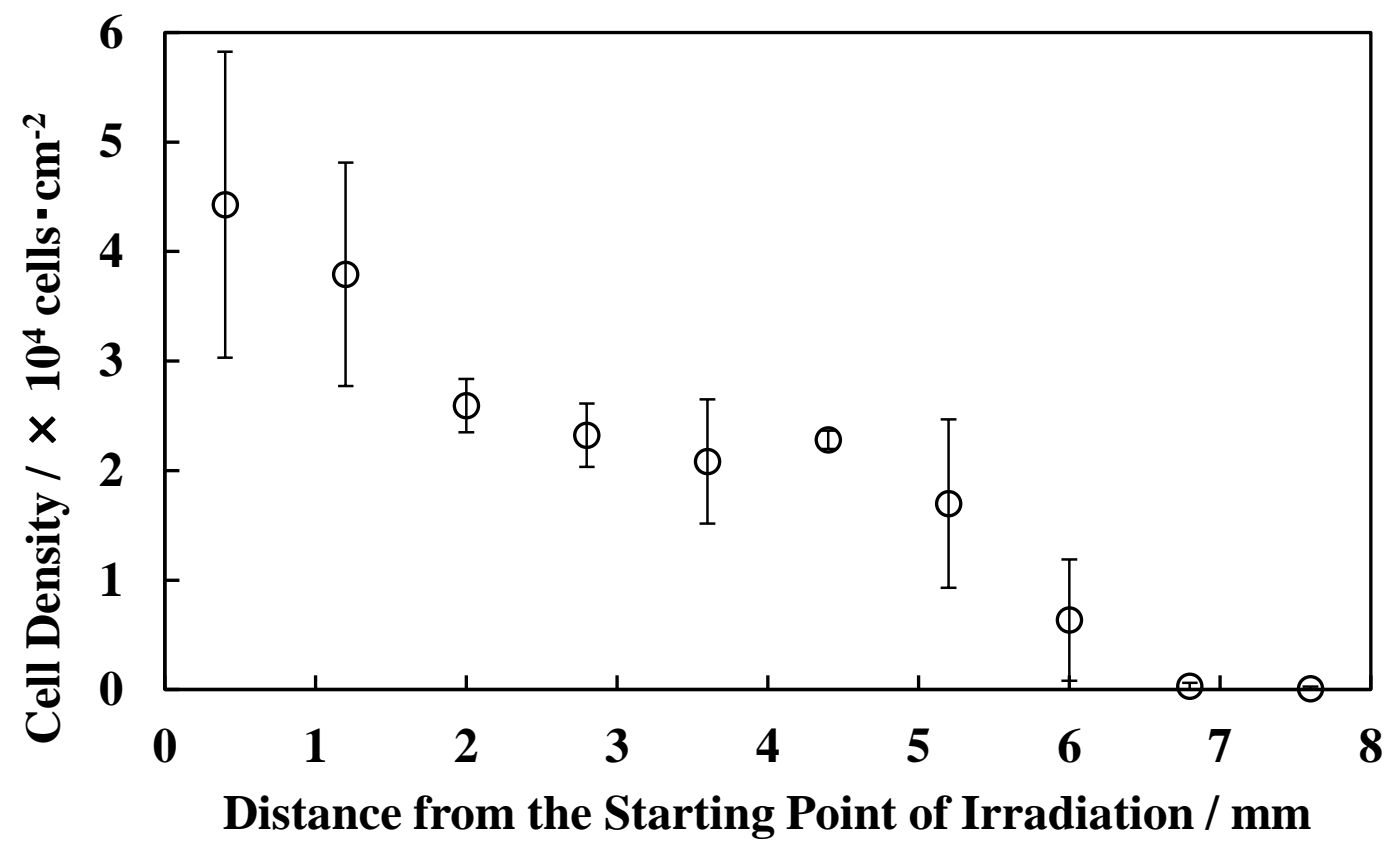

Figure 6. The density of $3 \mathrm{~T} 3$ cells adhered onto the gradated PCMB brushes at various distances from the starting point of irradiation. The data are shown as mean value \pm standard deviation for three independent samples. 
(a)<smiles>C=C(C)C(=O)OCC[N+](C)(C)CC(=O)[O-]</smiles>

(b)<smiles>CCO[Si](CCCC(=O)OC(C)(C)Br)(OCC)OCC</smiles>

(c)<smiles>CCC(=O)OC(C)(C)Br</smiles>

Scheme 1. Chemical structures of (a)

1-carboxy- $N, N$-dimethyl- $N$-(2-methacryloyloxyethyl)methanaminium hydroxide inner salt (CMB, GLBT $\left.{ }^{\circledR}\right)$, (b) 3-(2-bromo-2-isobutyryloxy)propyltriethoxysilane (BPE), and (c) Ethyl 2-bromoisobutyrate (EBiB). 
(a)

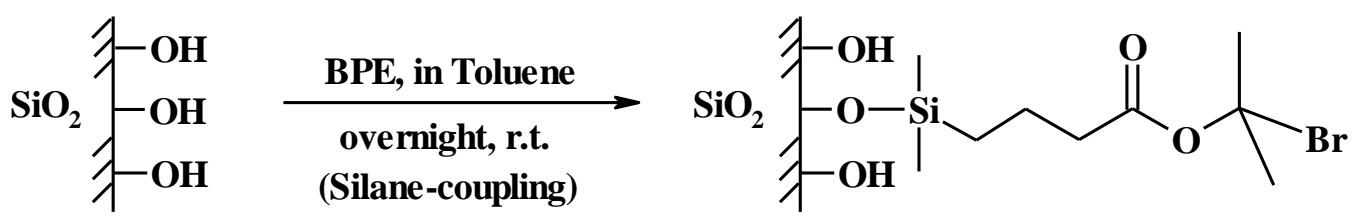

(b)<smiles>CC(C)(Br)OC(=O)CCC[Si](C)(C)OC(C(=O)O)C(C)(C)O</smiles><smiles>CCC(=O)OC(C)(C)C(C)(C)CC(C)(C)C(C)(C)C(=O)OCC[N+](C)(C)CC(=O)[O-]</smiles>

Scheme 2. Preparation of (a) BPE SAM by a silane-coupling reaction and (b) PCMB brush-modified substrate via SI-ATRP, and accompanying polymerization of free PCMB. 


\section{For Table of Contents}

Graft Density
Protein Adsorption

Cell Adhesion

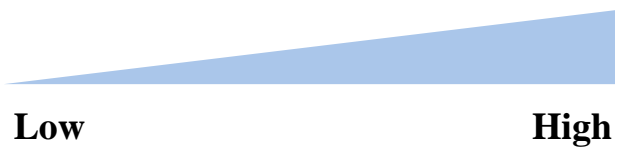

High

Low
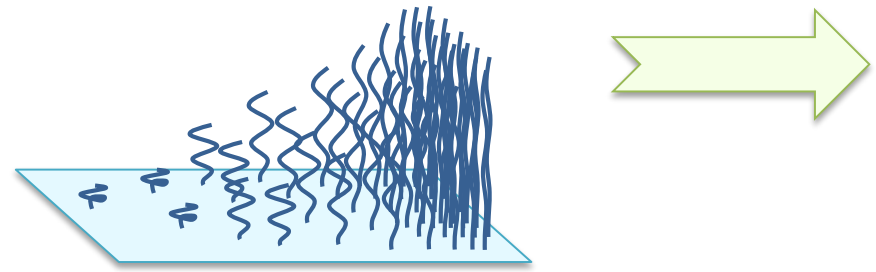

Cell

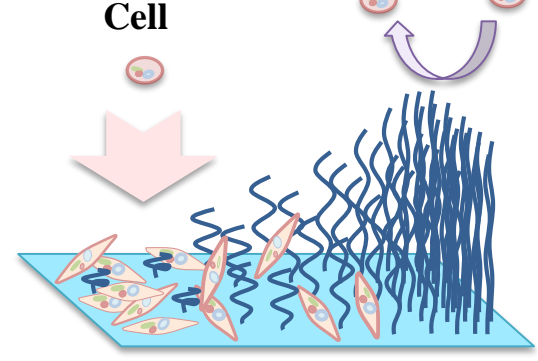

Gradation of Zwitterionic Polymer Brush 